\title{
STRATEGIC DESIGN OPPORTUNITIES TO INCREASE SUSTAINABLE FASHION AWARENESS AND BEHAVIOUR
}

\author{
Das, Marie; \\ Herweyers, Laure; \\ Moons, Ingrid; \\ Du Bois, Els \\ University of Antwerp
}

\begin{abstract}
Fast fashion, with its focus on cheap clothing and everchanging trends, has an enormous negative environmental and social impact. Despite rising consumer awareness and slow fashion as an emerging trend, many consumers often still rely on fast fashion. This research aims to create insights into why customers keep returning to fast fashion and what is holding them back from buying sustainable fashion. This is done through a quantitative survey $(\mathrm{n}=521)$ and qualitative semi-structured interviews $(n=9)$. Based on the findings, opportunities are defined for designers on how, where, and when to intervene, and on which target group to focus. The main obstacles that counter slow fashion are (i) a lack of understandable and clear information, (ii) the price or available budget, and (iii) the importance of social influence. Strategic design interventions should focus on educating eco-conscious and socialconscious customers based on their personal definition of sustainable fashion. By providing in-store information during time of purchase, designers can create new shopping experiences, educate customers using a positive note and build customer relations with the retailer. Further research should extend these insights with retailers' perspectives.
\end{abstract}

Keywords: Sustainable fashion, Consumer awareness, Human behaviour in design, Circular economy, Sustainability

\section{Contact:}

Herweyers, Laure

University of Antwerp

Product Development

Belgium

laure.herweyers@uantwerpen.be 


\section{INTRODUCTION}

Everyone wears clothes. It is part of our daily lives and next to protecting us from weather and other external influences, it has become a way to express ourselves. The impact of the fashion industry increased significantly over the last decades: between 2000 and 2015, the clothing industry doubled its sales, with more than 100 billion units sold in 2015 (Ellen MacArthur Foundation, 2017). In 2018, the global apparel market was estimated to be worth approximately 1,52 trillion USD in 2020 (Statista, 2020), employing about 300 million people along the entire value chain (Ellen MacArthur Foundation, 2017). This is in contrast with the fact that, people nowadays are spending less and less on clothing, and that since 2000, there has been a gradual decrease in the number of times an item of clothing is worn before it is ceased to be used (Ellen MacArthur Foundation, 2017). The household expenditure on clothing and footwear fell from 30\% in 1950 to only 5\% in 2020 (Niinimäki et al., 2020). In other words, people buy more garments at very low prices, resulting in them wearing each item only a few times. This can be attributed to the phenomenon of 'fast fashion' (Ellen MacArthur Foundation, 2017). Fast fashion is a business model that mass-produces clothing very rapidly with a swift turnaround of styles. It takes high fashion designs right of the catwalk and manufactures it at very low prices (Bick, Halsey and Ekenga, 2018). In this way, it satisfies the consumer to be fashionable at any given time at a low economic cost (Henninger, Alevizou and Oates, 2016). Unfortunately, because of the quick change of trends and the low prices, consumers attach less value to their clothes, which turns clothing into a disposable product (Linden, 2016). After their short lifetimes, $73 \%$ of all produced garments end up on landfill or are incinerated, $12 \%$ are used for cascaded recycling, $2 \%$ get lost during collection and processing, and $12 \%$ of the material is lost in production. Less than 1\% are used for closed-loop-recycling (Ellen MacArthur Foundation, 2017). It is obvious that the concept of fast fashion raises some serious ethical and environmental issues. (Mukherjee, 2015).

Annually, 53 million tons of fibres are produced for the production of clothing. The linear production process of fabrics uses primarily non-renewable sources, consequently puts pressure on resources, and pollutes and degrades the natural environment (Ellen MacArthur Foundation, 2017). Its environmental impact is significant: the fashion industry emits more carbon than all international flights and maritime shipping combined, accounting for $10 \%$ of the global carbon emissions and being the second-largest consumer of water (UNEP, 2018). On top of this, it is responsible for approximately $20 \%$ of all industrial water pollution (Niinimäki et al., 2020), plus the uncounted impact of the washing of synthetic clothes, resulting in the release of microfibers that are not only prominent in waterways but also on land and in the air (Leonas, 2018).

Also from an ethical perspective, large issues appear regarding the fashion industry. Augmented by the consumers' expectation for cheaper clothing as well as by globalization, the fashion industry has become very dependent on low-cost countries (LCC), such as China and India for the production of their goods (Linden, 2016). In combination with the short lead time (Pookulangara and Shephard, 2013), this often results in suppliers squeezing their workers' wages, demanding extensive overtime work and subjecting workers to (verbal or other) abuse when targets are not met (Anner, 2019). Sadly, modern slavery is frequently associated with this industry (Clay, 2013), which is strengthened by the fact that developing countries have less stringent regulations compared to developed countries resulting in unfair and dangerous working conditions (Mukherjee, 2015). The ethical issues of the fashion industry are getting more and more attention after the various exposures, such as the collapsed factory in Bangladesh, killing 1138 garment workers in 2013 (Hoskins, 2015), or the messages found in Zara clothes, written by garment workers declaring they were not getting paid for their work (Young, 2017). This caused a lot of commotion with the public and is increasing the consumers' awareness of the impact of the fashion industry (Westervelt, 2015). Consumers indicate a need for more sustainable clothing (Henninger, Alevizou and Oates, 2016). A new movement called 'slow fashion' positions against fast fashion. Slow fashion describes longlasting, high-quality clothes that are locally manufactured and primarily made from sustainably sourced and fair-trade fabrics. Slow fashion is not a substitute for fast fashion but rather a different kind of business conduct (Štefko and Steffek, 2018), which is (usually) more expensive than fast fashion in order to ensure that customers attach more value to their clothing again and refrain from discarding them so quickly (Jung and Jin, 2016), but also to pay for fair production conditions. Despite the rising awareness and demand for fair and environmental-friendly clothing, many 
customers are still attracted to fast fashion (Pookulangara and Shephard, 2013). Several studies have indicated that consumers have insufficient access to centralized information on sustainable fashion (Sproles, Geistfeld and Badenhop, 1978; Dickson, 2000), lack access and knowledge concerning companies' transparency (Bhaduri and Ha-Brookshire, 2011), and have little eco-fashion clothing available in their direct surroundings (Moisander, Markkula and Eräranta, 2010; Munir, 2020). Fashion is very sensitive to temporary trends and brand associations (Munir, 2020), which makes successfully promoting durable, ethical clothing, often from less well-known brands, more challenging. A gap in current research is the lack of a comprehensive portrait of slow-fashion consumers (Štefko and Steffek, 2018), which is necessary to define design opportunities for specific clusters of potential consumers. On top of that, little research has covered the relationship between sustainable clothing consumption and self-perception (McNeill and Moore, 2015) which is usually a main driver for wearing specific (branded and designed) clothes (Legere and Kang, 2020).

Often people have good intentions to buy sustainable clothes, but fail to translate this into their actual behaviour. This intention-behaviour gap between values and everyday actions (Sheeran and Webb, 2016) is influenced by several variables related to the broader field of behaviour change, such as personal and social norms, attitudes, and perceived behavioural control, as described by the Reasoned Action Approach (Jung and Jin, 2016)(Fishbein and Ajzen, 2010). According to the more recent Comprehensive Action Determination Model (CADM) (Klöckner and Blöbaum, 2010), habits should also be included to create a general model for predicting both one-time and repeated behaviour change. The CADM is often used in design research studies in the field of Design for Sustainable Behaviour (Zachrisson and Boks, 2010). In this study, the CADM model is deployed to investigate these barriers for behaviour change on the topic of slow fashion. Consequently, it offers a sturdy basis to structure our research.

\subsection{Aim of the research}

This research aims to find insights into why many consumers are still focusing on fast fashion despite the increasing awareness. The goal is to identify the thresholds and understand how strategic design interventions can facilitate the transition towards sustainable fashion behaviour. The general research question is: 'How can design support the increase of sustainable consumer-awareness and sustainable behaviour within the topic of fashion?'. Based on this main question, we formulated different subresearch questions that were investigated in this study:

RQ1: How can 'perception of self' be integrated in design interventions? (Why)

RQ2: What are the variables (identified by CADM) that influence sustainable fashion awareness and behaviour the most? (What)

RQ3. What are the critical moments during the user journey? (E.g. Purchase, usage, disposal...) (When) RQ4. In what phases or touchpoints of the user journey can designers intervene? (E.g. In-store, online, advertisement...) (Where)

RQ5. Who should designers focus on in possible design interventions? What is the most interesting target group to focus on first when designing a solution? (Who)

\section{METHODS}

The executed research is twofold. Both quantitative (survey) and qualitative (semi-structured interviews) studies were done to triangulate the obtained results and complement the quantitative data with a more in-depth, qualitative exploration. Both research activities took place at the same time. The survey's purpose was to obtain general information on a large sample of the population, while the semi-structured interviews were meant for discovering new critical aspects and exploring opportunities.

\subsection{Survey}

A structured survey was constructed and distributed using Qualtrics software. The survey had a total of 22 questions. To start, specific demographic questions (age, gender, profession, income and annual expenditure on clothing) were asked for later statistical processing and generalization of the results. The following questions were set up and structured based on the four variables from the CADM model (normative processes, habitual processes, intentional processes, and situational influences,), and supplemented with the NEP scale (Dunlap et al., 2000) to assess (ecological) 
attitudes. The first part covered the respondents' knowledge, addressed their personal definition of sustainable fashion, their knowledge on the environmental impact of the fashion industry, and their choice on the most sustainable option out of several dilemma's. Next, the thresholds were assessed that people encounter while buying clothes, preventing them from choosing the most sustainable option. The final part covered the values and social influences people experience while choosing and buying new clothes.

Respondents were invited to participate in the survey with a link to the questionnaire sent by email or social media. Snowball sampling was used as a method of distribution. This way, we could reach a large number of participants at a relatively low cost. We are aware that this sampling method can limit the level of generalization that can be reached with any level of confidence. The sampled population consists of Flemish respondents of all ages. The survey was completed by 521 respondents. $74 \%$ were female and the average age of the respondents was 30 years old. $37 \%$ of the respondents were students and $27 \%$ worked full-time. $30 \%$ of the highest obtained degree was a high school degree, followed by professional bachelor's degree (22\%) and master's degree (22\%). The NEP-scale did not show much variance between different respondents. All respondents show a relatively high concern and awareness of the environmental issues.

\subsection{Semi-structured interviews}

From a qualitative perspective, semi-structured interviews were conducted with nine respondents in total. The interviews were done in Dutch with Flemish consumers, using Skype, and lasted more or less 45 minutes per respondent. Besides verifying the results from the survey, the interviews went deeper into the motivators and restraints for individual purchase behaviour.

The selection of participants for the semi-structured interviews was based on a set of four types of fashion consumers, to reach a diverse group of respondents and avoid focusing on one specific type of consumer from the beginning. Group 1 and $2(\mathrm{G} 1, \mathrm{G} 2)$ are consumers that are aware of the environmental impact of the fashion industry. The difference between both groups is that G1 shows this concern by mostly buying second-hand clothes. G2 shops more consciously by buying less clothes and looking for high quality, timeless pieces. Group 3 (G3) enjoys shopping and buying new and stylish, but inexpensive clothes. They mainly shop at fast fashion stores. Lastly, group 4 (G4) consists of very stylish customers that like unique and expensive pieces of clothing and combine this with inexpensive basics. Regarding the explorative nature of the research, no specific types of consumers were excluded.

The interview was organised in different sections. During a short introduction, the interviewees were asked to introduce themselves according to their fashion preferences and shopping behaviour. The second part consisted of several warm-up questions, allowing the interviewee to talk about their favourite garment and what makes it difficult or easy to discard a garment. The third part focused more on the topic of the fashion industry and its environmental impact. The research method 'card sorting' was introduced to analyse which associations people make (Spencer, 2004). Each interviewee was given 17 cards with different themes regarding the topic of the interview and was asked to divide these cards into logical categories. Afterwards, they were asked to label the categories. The number of categories was up to the interviewee to decide. Next, the personal definition of sustainable fashion was asked. Afterwards, we discussed the interviewee's personal user journey of the pre-purchase up until disposal of a recently bought garment. At each stage of the user journey, we went deeper into the (sustainable) behavioural choices. Following questions were asked and discussed at every stage of the user journey: What was the reason for making this decision? Was sustainability an important factor? How did you feel while doing this? During the part 'Life stories \& cases', the interviewee was asked to talk about a moment they were struggling with making the more sustainable decision. Next, the interviewee was asked to indicate their awareness of the environmental issues of the fashion industry and how they feel about it. To conclude the interview, ideas and improvements for a more effortless way to make more sustainable choices were discussed.

All interviews were transcribed and coded using Nvivo software to achieve semantic categorisation. Each comment was classified in different subjects called nodes. Between each node a relation was defined for the purpose of mapping out a clustermap, clustering each node into coherent topics. To verify the outcome of the interviews, the results were compared with existing literature. 


\section{RESULTS}

\subsection{Survey}

\subsubsection{Descriptive results}

When respondents were asked what sustainable fashion means to them, the most frequent answer was 'lessened environmental impact' (20\%), followed by 'high product quality' (18\%). Besides that, respondents had the option to fill in an aspect of sustainable fashion that was not given. A major part of the additional aspects was about prolonging the lifecycle of a garment or buying timeless clothes. People consider the environmental impact of a garment more at their disposal (59\% of the respondents answered 'often' or 'always') than at the purchase (38\%) or while using them (38\%). Almost $30 \%$ of the respondents stated that 'it is nice to have something new to wear' as the main reason to buy new clothing. The second most important reason is that the 'old garment is worn down' (27\%), followed by 'because I needed it' (19\%). When asked what the main reason is to discard a piece of clothing, surprisingly only $2 \%$ gave the answer 'it is not trendy anymore', initially contradicting the concept of rapidly changing styles specific to fast fashion. In another question, this is confirmed by only $17 \%$ stating to be very affected by trends. In addition, more than half of the respondents (59\%) said that they are willing to pay more for sustainable fashion items. Regarding access to information, 52\% mentioned that they don't know enough sources and influences to learn how to shop more sustainably. It is remarkable that $60 \%$ of the respondents think they are not well informed by both regular and social media on the environmental impact of the fashion industry.

\subsubsection{Statistical analysis}

The responses were processed in SPSS software by doing a factor- and cluster analysis. first, a factor analysis was applied to five questions: G1 (Habits), C1 (constraints), I1 (intentions), S1 (social influences) and N1 (NEP-scale). These questions consisted of 5 or more sub-questions using a Likert-scale. The aim was to reduce these variables to only a few factors to use for a clusteranalysis. G1 was reduced to 2 factors: (1) focus on user-journey and (2) focus on production, C1 was reduced to 2 factors: (1) effort and (2) need, I1 was reduced to 1 factor: Intentions and N1 was reduced to 1 factor: environmental consciousness. S1 could not be reduced to a factor because Cronbach's Alpha $=0,397<0,70$.

Subsequently a cluster analysis was applied to group the respondents into consumer groups. The input for this analysis were the factors 'focus on user-journey', 'focus on production' and the variable where respondents had to indicate how knowledgeable they consider themselves regarding the environmental impact of the fashion industry. The factor 'environmental consciousness' was not used as an input because there was not enough significant variance between the responses. As a result, the respondents were grouped into four consumer groups presented by the personas that are shown in Figure 1. These four groups are (i) Eco Warriors, (ii) Social Conscious, (iii) Eco Conscious, (iv) Je m'en fous. 


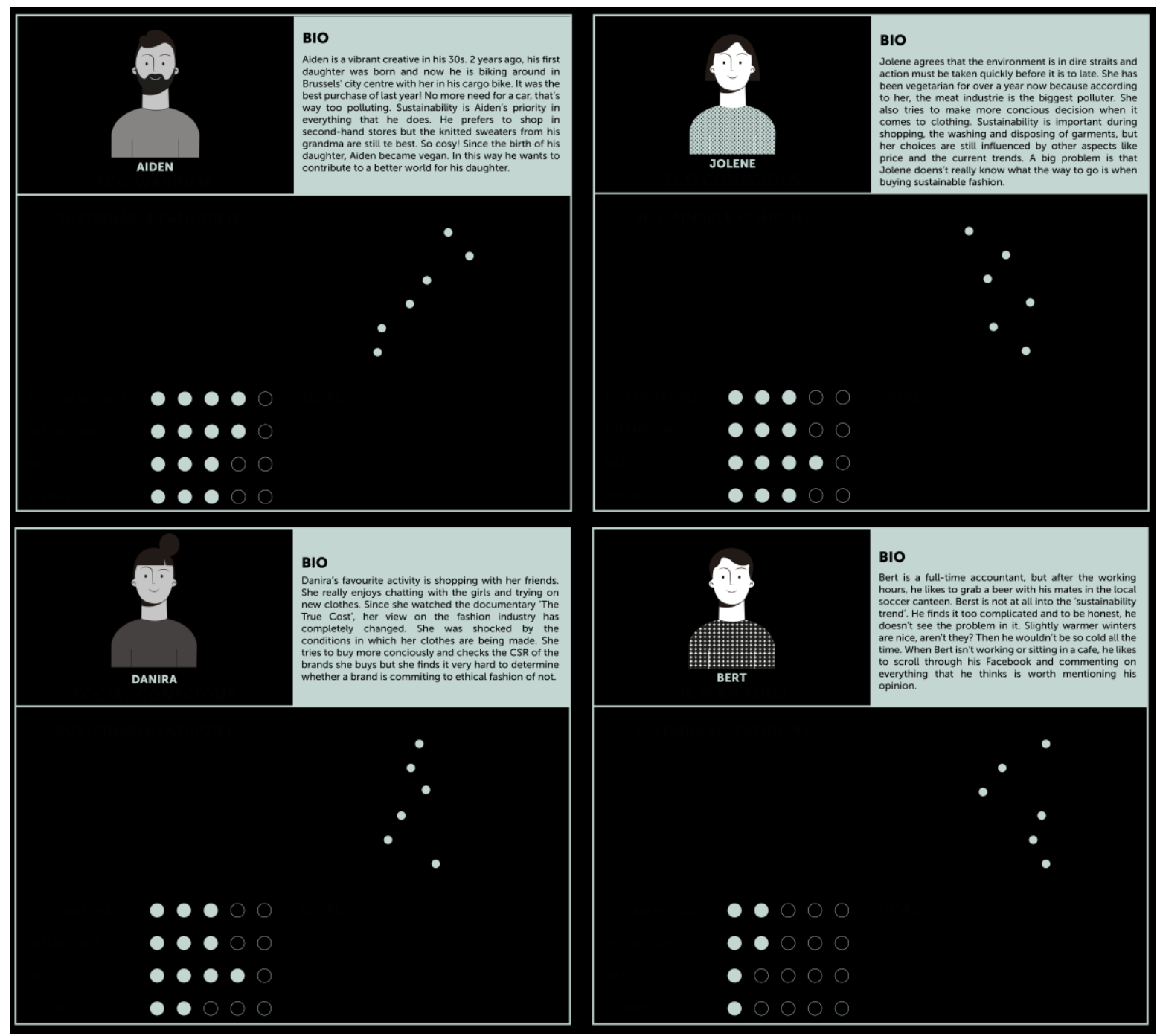

Figure 1. Four persona's with their specific characteristics

Finally, an ANOVA was applied to check whether there is a significant difference in intentions between the four groups. The ANOVA showed that there is indeed a significant difference in intention between all groups except between Social Conscious and Eco Conscious. A possible explanation is that both groups closely resemble each other, except on their definition of sustainable fashion. Eco Conscious focuses more on the environmental impact whereas Social Conscious focuses more on the working conditions, wages, etc.

\subsection{Semi-structured interviews}

In total, 1139 references were coded in 52 different nodes. The total amount of references for each node was counted in order to create an overview of the most cited topics. These are: (1) money, (2) information, (3) look and (4) materials.

Money (90x): This is mainly about the cost of a garment. The price is one of the most important aspects considered during the purchase of a piece of clothing. Often there is a mental trade-off between price and quality. Furthermore, there is a strong association between sustainable fashion and high prices.

Information (80x): This node coincides closely with the node 'raising awareness' (33x) and 'social influence' $(22 \mathrm{x})$. All the interviewees quoted that there is too little information available. Arguments behind this statement are: (1) they don't actively search for information, (2) the available information is unclear and fragmented, or (3) the information doesn't reach the consumer. The subject is not discussed very often between peers and they don't know how to start buying sustainable fashion. Having enough knowledge on the impact is one of the main reasons for making a certain choice. One interviewee talked about teaching a course on sustainability in elementary and high school. 
Look (78x): The look of a garment is a factor that determines whether people buy, use, wash, or dispose a certain product or not. It is a factor that is considered during each stage of the user journey. The node 'fit' $(14 \mathrm{x})$ is closely related to this node.

Materials (62x): It is important for consumers to know what materials their clothes are made of. Natural fibres are often preferred. On the other hand, the interviewees indicate to have little knowledge about the different materials and their characteristics, making it hard to make a thoughtful decision.

During the interviews, the interviewees were asked for their personal definition of sustainable fashion. Four aspects kept returning: A long lifecycle (mentioned by all the interviewees), the use of 'the right' resources (mentioned 6 times), a fair process (mentioned 6 times), a neutral impact on the environment (mentioned 6 times).

It was apparent that most critical moments were situated at the time of purchase of new clothing. Seven out of the nine interviewees indicated that most impact could be achieved when consumers buy more consciously.

\subsubsection{Card sorting}

To analyse the card sorting, the number of times cards were placed together in a category were counted. Based on this counting, six general categories related to the fashion industry and its environmental impact could be distinguished: (1) Price-quality, (2) materials, (3) social aspects, (4) ecological aspects, (5) lifecycle and (6) sustainable technologies.

\section{Discussion}

\subsection{Definition of sustainable fashion and perception of self (why)}

There is a resemblance between the definitions of sustainable fashion given during the semistructured interviews and the ones entered in the survey. According to the respondents, a long lifecycle and lessened environmental impact are the most important aspects that make a garment sustainable. The aspect 'long lifecycle' was not given as an option in the survey, but 'high quality' and the option 'prolonging the lifecycle' suggested by respondents provided similar alternatives. High quality products are often used longer than products of lower quality because they don't wear down so quickly, resulting in a longer lifecycle. It is important to acknowledge that the environmental issues are multifaceted and that every individual has a different view on how to buy sustainable fashion (Jung and Jin, 2016). This is confirmed by McDonald et al. (2012), stating that it is important to create a more complex conceptualization of the consumers and their journey to sustainable consumption rather than describing one type of green consumer (McDonald et al., 2012). During the further development of solutions, it is more important to focus on what a consumer's personal definition is rather than generalizing it to one aspect. Therefore, we consider it as an opportunity for design to strengthen people's individual perspective and enable to enlarge this definition by new insights and understandings.

\subsection{Variables that influence sustainable fashion awareness and behaviour (what)}

During the semi-structured interviews, it is stated that the most important reason why the interviewee does not (yet) buy sustainable fashion is due to a lack of information, confirming previous research (Sproles, Geistfeld and Badenhop, 1978; Dickson, 2000). This is in line with the results of the survey. A possible explanation is that the information is so abundant that it is not manageable and understandable. On the other hand, information is not available on regular and social media. This could indicate that people fail to actively educate themselves on the subject unless they are very passionate about it. During the interviews, interviewees stated that information should reach them and that they want to be educated in an effortless and doable manner. In conclusion, buying sustainable fashion can be facilitated through design by providing consumers clear, unambiguous information that is understandable and manageable.

As previously mentioned, the issues the fashion industry faces today are multifaceted. In order to maximize the education of the customer and create an inspiring experience, various design solutions are needed to make it easy for customer to learn things based on their personal definition of sustainable fashion. This way, the customer can select information that applies to their personal definition and learn more about the topic. 
Price was given as a very important reason whether or not to buy a certain garment, explaining the popularity of cheap fast fashion clothes. Therefore, during the support of making sustainable fashion choices, it is important to take the consumer's budget into account.

Social influence is very important during the decision-making processes. This was both apparent during the semi-structured interviews and the survey and is also confirmed by CADM, which states that the importance individuals attach to the opinion of others and the social environment influences their behavioural intent.

\subsection{Critical moments during the user journey (when)}

Critical moments are more present during the purchase of clothing. A conscious purchase has an influence on the production process and the remainder of the user journey. Consumers can put pressure on brands to give more attention to sustainability in the manufacturing phase by demanding and buying sustainable garments. On top of that, when a garment is bought more consciously, consumers might value the worth of the garment more, which encourages them to use it longer and more consciously. During this stage, consumers experience more social influence than during other stages of the user journey. This is an opportunity for designers to capitalize on.

\subsection{Where can designers intervene during the user journey? (where)}

An interesting line of thought is to focus on better in-store information to educate the customers about sustainable fashion. It was found that the time gap between informing the customer and them actually buying (sustainable) clothing should be short. Consequently, informing design interventions are of larger interest when the information is provided in store than for example at home. Additionally, there is also an opportunity to create an informative and amusing shopping experience that does not motivate to buy more, but to select the best suitable piece. Another benefit is that salespeople can play a big part regarding social influence. Customer relations can arise, and retailers can quickly respond to the needs of their customers. In their turn, retailers can pass this information to the wholesale and the brands they buy. There are two important things that should be taken into account when shoppers are informed in-store: (i) it is critical to inform customers in a positive way, making sure they do not feel guilty about certain choices they make. Negative feedback can create counter-effects. (ii) Money is one of the most important aspects considered during the purchase of clothing, which makes the budget customers have to spend on clothing an important variable.

\subsection{Choice target group (who)}

'Eco Conscious' and 'Social Conscious' were both chosen as target group for further design of a potential solution. These consumer groups are chosen because they are aware of the environmental impact and show an intention to buy sustainable fashion. They indicate the need for guidance when doing so. We argue not to focus on the 'Je m'en fous' group initially, because it is a group of consumers that renounce showing any intention to buying sustainable fashion. They are not easily convinced and might even counteract. If we focus too much on this group, other interesting opportunities will be overlooked. Neither should the focus be on the 'Eco Warriors'. They already buy sustainable fashion and know a lot about sustainability.

Regarding the limitations of this study, snowball sampling was used to distribute the survey, which limits the possibilities for generalization since equal distribution cannot be ensured. The overwhelming majority of the respondents were female. From this can be concluded that women show more interest in the topic of 'sustainable fashion' and are more involved than men. We are aware that the collected data is not a representative sample of the population. Therefore, we cannot generalize these findings to the whole population, but interesting design opportunities could be identified that deserves further development and reasoning to support this young female part of the population.

\section{CONCLUSIONS AND RECOMMENDATIONS}

As a result of a raising consumer awareness on the environmental impact of the fashion industry, there is an increasing demand for sustainable fashion. However, customers find it hard to translate this need into actual sustainable behaviour. A quantitative (survey) and qualitative (semi-structured interviews) study were done and triangulated to achieve insights into strategic design opportunities to support consumers 
in the decision-making process and behaviour change towards sustainable fashion. Based on this research, it could be concluded that the most important reasons for the intention behaviour gap are (i) lack of clear and manageable information, (ii) the price and budget of consumers and (iii) the social influence during the purchase of clothing. Consequently, the following design opportunities could be identified:

- Environmental issues of the fashion industry are multifaceted. Design should take customers personal definition of sustainable fashion into account when providing information and enable consumers to extend this personal definition. An example could be a retail store that instead of being organised by brand, clothing is organised by the different foci or definitions of sustainability. This makes it easier for the consumer to shop in the part that resembles their personal definition.

- Eco-conscious and social-conscious people are willing to change behaviour but mainly lack the appropriate knowledge and support to achieve this. This necessary knowledge can be transferred to potential consumers by designing a communication tool, centralizing relevant information and providing unprejudiced advice to customers.

- In-store design of information is an interesting line of thought to educate the customer as it links closest to the purchasing process, and shortens the time between the intake of information and the act of decision making. This can be achieved through both low tech (e.g. by labelling) and high tech design solutions (e.g. by a smart mirror that gives real time information about the garment that the customer is trying).

- Design should make use of positive information to enthuse consumers rather than negative data in order to prevent drop out. The opportunity of this positive experience has a large potential to increase the awareness of the impact of fashion. Projections, visuals, or sounds can create a metaphorical environment or 'mirror' for the customer to experience their (un) sustainable choices.

As this research was limited to the identification of the consumers' barriers, further research is needed to question all other stakeholders to create insights in the problems that, for example, retail stores and salespeople experience during this process and how they view sustainable consumer behaviour. Testing several prototypes that apply these recommendations can provide more concrete information on the effectiveness of specific design properties.

\section{REFERENCES}

Anner, M. (2019) 'Predatory purchasing practices in global apparel supply chains and the employment relations squeeze in the Indian garment export industry’, International Labour Review, 158(4), pp. 705-727. https://dx.doi.org/10.1111/ilr.12149.

Bhaduri, G. and Ha-Brookshire, J. E. (2011) 'Do Transparent Business Practices Pay? Exploration of Transparency and Consumer Purchase Intention', Clothing and Textiles Research Journal. SAGE PublicationsSage CA: Los Angeles, CA, 29(2), pp. 135-149. https://dx.doi.org/10.1177/0887302X11407910.

Bick, R., Halsey, E. and Ekenga, C. C. (2018) 'The global environmental injustice of fast fashion', Environmental Health: A Global Access Science Source. Environmental Health, 17(1), pp. 1-4. https://dx.doi.org/10.1186/s12940-018-0433-7.

Clay, A. (2013) Modern Day Slavery in the Fashion Industry.

Dickson, M. A. (2000) 'Personal Values, Beliefs, Knowledge, and Attitudes Relating to Intentions to Purchase Apparel from Socially Responsible Businesses', Clothing and Textiles Research Journal. International Textile and Apparal Association, 18(1), pp. 19-30. https://dx.doi.org/10.1177/0887302X0001800103.

Dunlap, R. E. et al. (2000) 'New Trends in Measuring Environmental Attitudes: Measuring Endorsement of the New Ecological Paradigm: A Revised NEP Scale', Journal of Social Issues. Blackwell Publishing Inc., 56(3), pp. 425-442. https://dx.doi.org/10.1111/0022-4537.00176.

Ellen MacArthur Foundation (2017) A new textiles economy: Redesigning fashion's future, Ellen MacArthur Foundation.

Fishbein, M. and Ajzen, I. (2010) Predicting and Changing Behavior: The Reasoned Action Approach. Psychology Press.

Henninger, C. E., Alevizou, P. J. and Oates, C. J. (2016) 'What is sustainable fashion?', Journal of Fashion Marketing and Management, 20(4), pp. 400-416. https://dx.doi.org/10.1108/JFMM-07-2015-0052.

Hoskins, T. (2015) 'Rana Plaza: are fashion brands responsible for those they don't directly employ?', The Guardian, April. 
Jung, S. and Jin, B. (2016) 'From quantity to quality: understanding slow fashion consumers for sustainability and consumer education', International Journal of Consumer Studies, 40(4), pp. 410-421. https://dx.doi.org/10.1111/ijcs.12276.

Klöckner, C. A. and Blöbaum, A. (2010) 'A comprehensive action determination model: Toward a broader understanding of ecological behaviour using the example of travel mode choice', Journal of Environmental Psychology. Academic Press, 30(4), pp. 574-586. https://dx.doi.org/10.1016/j.jenvp.2010.03.001.

Legere, A. and Kang, J. (2020) 'The role of self-concept in shaping sustainable consumption: A model of slow fashion', Journal of Cleaner Production. Elsevier Ltd, 258. https://dx.doi.org/10.1016/j.jclepro.2020.120699.

Leonas, K. K. (2018) 'Textile and apparel industry addresses emerging issue of microfiber pollution', Journal of Textile and Apparel, Technology and Management, 10(4), pp. 1-6.

Linden, A. R. (2016) An Analysis of the Fast Fashion Industry.

McDonald, S. et al. (2012) 'Individual strategies for sustainable consumption', Journal of Marketing Management, 28(3-4), pp. 445-468. https://dx.doi.org/10.1080/0267257X.2012.658839.

McNeill, L. and Moore, R. (2015) 'Sustainable fashion consumption and the fast fashion conundrum: fashionable consumers and attitudes to sustainability in clothing choice', International Journal of Consumer Studies. Blackwell Publishing Ltd, 39(3), pp. 212-222. https://dx.doi.org/10.1111/ijcs.12169.

Moisander, J., Markkula, A. and Eräranta, K. (2010) 'Construction of consumer choice in the market: challenges for environmental policy’, International Journal of Consumer Studies. John Wiley \& Sons, Ltd, 34(1), pp. 73-79. https://dx.doi.org/10.1111/j.1470-6431.2009.00821.x.

Mukherjee, S. (2015) 'Environmental and social impact of fashion: Towards an eco-friendly, ethical fashion', Journal of Interdisciplinary and Multidisciplinary Research, 2(3), pp. 22-35.

Munir, S. (2020) 'Eco-Fashion Adoption in the UAE: Understanding Consumer Barriers and Motivational Factors', Fashion Practice. Routledge, 12(3), pp. 371-393. https://dx.doi.org/10.1080/17569370.2020.1777729.

Niinimäki, K. et al. (2020) 'The environmental price of fast fashion', Nature Reviews Earth \& Environment. Springer US, 1(4), pp. 189-200. https://dx.doi.org/10.1038/s43017-020-0039-9.

Pookulangara, S. and Shephard, A. (2013) 'Slow fashion movement: Understanding consumer perceptions-An exploratory study', Journal of Retailing and Consumer Services. Pergamon, 20(2), pp. 200-206. https://dx.doi.org/10.1016/j.jretconser.2012.12.002.

Sheeran, P. and Webb, T. L. (2016) 'The Intention - Behavior Gap The Intention - Behavior Gap', Social and Personality Psychology Compass, 10(9), pp. 503-518.

Sproles, G. B., Geistfeld, L. V. and Badenhop, S. B. (1978) 'Informational Inputs as Influences on Efficient Consumer Decision-Making', Journal of Consumer Affairs. John Wiley \& Sons, Ltd, 12(1), pp. 88-103. https://dx.doi.org/10.1111/j.1745-6606.1978.tb00635.x.

Statista (2020) 'Market value of global apparel demand from 2005 to 2020 '.

Štefko, R. and Steffek, V. (2018) 'Key issues in Slow Fashion: Current challenges and future perspectives', Sustainability (Switzerland), 10(7), pp. 1-11. https://dx.doi.org/10.3390/su10072270.

UNEP (2018) Putting the brakes on fast fashion, UNEP.

Westervelt, A. (2015) 'Two years after Rana Plaza, have conditions improved in Bangladesh's factories?', The Guardian.

Young, S. (2017) 'Unpaid labourers are "slipping pleas for help into Zara clothes", Indepentent, November.

Zachrisson, J. and Boks, C. (2010) 'When to apply different design for sustainable behaviour strategies?', in Knowledge Collaboration \& Learning for Sustainable Innovation ERSCP-EMSU conference. 